67. Shenstone, A. G. $\quad 1970,1971$, J. Res. Nat. Bur. Std. (U.S.), 74A, 801; 75A, 335.

68. Sugar, J., Kaufman, V. 1972, J. Opt. Soc. Am., 62, 562.

69. Sugar, J., Meggers, W. F., Camus, P. 1972, J. Res. Nat. Bur. Std. (U.S.), 76A, in press.

70. Svensson, L. A. 1971, Phys. Scr., 4, 111.

71. Swartz, M., Kastner, S., Rothe, E., Neupert, W. 1971, J. Phys. B: At. Molec. Phys., 4, 1747.

72. Tondello, G. 1972, Astrophys. J., 172, 771.

73. Verges, J., Corliss, C. H., Martin, W. C. 1972, J. Res. Nat. Bur. Std. (U.S.), 76A, 285.

74. Widing, K. G., Sandlin, G. D., Cowan, R. D. 1971, Astrophys. J., 169, 405.

CH. MOORE-SITTERLY

Chairman of the Committee

\title{
COMMITTEE 5: MOLECULAR SPECTRA
}

\section{Compendia, bibliographies and atlases}

The period of time covered by this report saw the appearance of a number of important publications. Of primary importance has been the appearance of the second edition of Spectroscopic Data relative to Diatomic Molecules (1) preprared by an international team of spectroscopists under the direction of B. Rosen. About 700 diatomic molecules are covered. For each molecule most of the following are included: mode of production, wavelengths and classification of vibrational band heads, molecular constants, dissociation energies, perturbations, predissociations, ionization potentials, transition probabilities, and a detailed bibliography to 1969. As a follow-up to this enormous task, a group is preparing to produce annual critical abstracts and up-dates. A program is being written at Stockholm to catalogue data from this table, both by molecule and by wavelength. Several bibliographies have appeared or are in preparation. Carlos Suarez at La Plata has compiled via computer a Bibliography of Spectra of Diatomic Molecules, 1960-1970. It is in four parts; a few polyatomic molecules are also listed. The International Union of Pure Applied Chemistry publishes a Bibliography on the High Temperature Chemistry and Physics (2) which includes many interesting references to laboratory techniques, specific heats, transition probabilities, etc. T. M. Dunn at Michigan and T. Larsson and H. Neuhaus at Stockholm are maintaining bibliographies of hyperfine structures in diatomic molecules, David R. Lide of the Office of Standard Reference Data, N.B.S., has called attention to the new Journal of Physical and Chemical Reference Data, which will include compilations and reviews of interest to molecular spectroscopists. The bi-monthly Berkeley News letters are continuing; the mailing list has grown to cover 400 spectroscopists in various countries. Each bi-monthly issue includes a bibliography of papers on diatomic and simpler polyatomic molecules appearing in over 30 journals. R. W. Nicholls has continued the publication of the series of Identification Atlases of Molecular Spectra, the most recent covering the CO Fourth Positive System, VO, and the CN Red System; an atlas on the CN violet system is in preparation. Publication of the CRESS reports by Nicholls and his collaborators has continued; they include data on FranckCondon factors and related quantities for a long series of band systems. Lifetimes in gaseous diatomic molecules have been discussed in a recent article by Anderson (3). Finally a number of monographs of great value have appeared. They include: Rotational Structure in the Spectra of Diatomic Molecules by I. Kovacs (4), Far-infrared Spectroscopy by Moller and Rothschild (5), Microwave Molecular Spectra by Gordy and Cook (6), Rydberg series in Atoms and Molecules by Duncan (7), An Introduction to Molecular Spectroscopy by Herzberg (8), Low Temperature Spectroscopy by B. Meyer (9) and Revised Tables of Diatomic Molecular Constants by K. P. Huber (10).

\section{Molecular data}

Even if the discussion is limited to molecules of astrophysical interest, the research that has been completed is much too extensive for full coverage here. Reference should be made to the bibliographies listed above. A selection of recent analyses includes the following. 


\section{(a) Electronic band analyses and constants for diatomic molecules}

On molecules involving carbon, Fay et al. have improved the molecular constants of the Red System of CN (11), while Kepa and Rytel have found a new band system (' $\left.\pi-{ }^{\prime} \pi\right)$ of CO (12). An absorption spectrum of $\mathrm{CO}$ in the $600-1020 \AA$ region has been investigated by Ogawa and Ogawa (13), and isotopic CO bands by Simmons and Tilford (14) and Kepa et al. (15). Green (16) has calculated potential energy curves for $\mathrm{CH}^{+}$, while Meinel (17) reports a possible new $\mathrm{C}_{2}{ }^{+}$spectrum. Among the diatomic oxides, Miescher has continued his extensive investigations of the absorption spectrum of NO (18) while Brown et al. have studied infrared magnetic dipole transitions of NO (19). Molecular constants of $\mathrm{OH}$ and $\mathrm{O}_{2}$ have been calculated by Mizushima (20) and Welch and Mizushima (21). Moore and Richards (22) have re-analysed the $A^{2} \Sigma^{+}-X^{2} \pi$ ) system of $\mathrm{OH}$. The vacuum ultraviolet spectrum of $\mathrm{SiO}$ has been investigated by Elander and Lagerqvist (23), while Cornet and Dubois report on a new electronic transition in SiO (24). Green has analysed the rotational structure of the $\mathrm{C}^{2} \pi-X^{2} \pi$ transition of $\mathrm{LaO}(25)$, and investigated low-lying electronic states of $\mathrm{LaO}, \mathrm{YO}$, and $\mathrm{ScO}(26)$. A new ${ }^{1} \Sigma-{ }^{1} \Sigma$ band system of TiO has been reported by Phillips and Davis (27) and extended by Lindgren (28), and a further $\left({ }^{1} \Delta-{ }^{1} \Delta\right.$ ) TiO system has been reported by Linton (29). Satellite bands of the $\gamma^{\prime}$-system of TiO have been analysed by Phillips (30). The ionization potential of $\mathrm{H}_{2}$ has been re-examined by Herzberg and Ch. Jungen (31); Stephens and Dalgarno have calculated the spontaneous radiative dissociation in $\mathrm{H}_{2}(\mathbf{3 2})$, while Crosswhite (33) has edited the hydrogen molecule tables of G. H. Dieke.

(b) Transition probabilities, lifetimes, intensities

Aert Schadee has investigated the normalization of the Hönl-London factors and the definition of the molecular electronic transition moment (34). A great amount of work has been done recently on $\mathrm{CO}$ and $\mathrm{CO}^{+}$. In the case of $\mathrm{CO}$, Ajello has measured emission cross-sections by electron impact in the $1260-5000 \AA \AA$ region (35); the intensity of the Cameron system by Pilling, Bass and Braun (37) and the infrared rotation-vibration spectrum by Roux et al. (38) and Lowder (39). Oscillator strengths in the $\mathrm{CO}^{+}$comet tail system have been derived by Jain (40) and its electronic transition moment by Maier and Holland (41). Judge and Lee (42) have recently carried out an extensive computation of electronic transition moments and absolute cross sections for a number of $\mathrm{CO}^{+}$transitions. Collisional transition probabilities and Franck-Condon factors for excited states and transitions of $\mathrm{CN}$ have been calculated for the red system of $\mathrm{CN}$ have been carried out by Johnson, Marenin and Price (45) and Querci et al. (46); the latter also include other systems of $\mathrm{CN}$ and $\mathrm{C}_{2}$. Among the large number of recent studies of various aspects of the spectrum of $\mathrm{H}_{2}$, there has appeared a calculation of infrared emissivities of $\mathrm{H}_{2}$ and $\mathrm{HD}$ carried out by Dalgarno and Wright (47). The intensities and transition probabilities of electronic systems of NO have been investigated by Copeland (48), Michels (49), Hasson and Nicholls (50), and Farmer, Hasson and Nicholls (51), while work on its infrared rotation-vibration spectrum has been carried out by Bubert (52) and Moskalenko and Mirumyants (53). Also in the infrared, the intensities of $\mathrm{OH}$ bands have been observed by d'Incan, Effantin and Roux (54) and Murphy (55). Hasson and Nicholls (56) and Jarmain (57) have observed $\mathrm{O}_{2}$ ultraviolet bands and calculated Franck-Condon factors for the Herzberg system. Among the metallic oxides, mention should be made of an investigation of absorption coefficients in the infrared vibration-rotation spectrum of FeO by Fissan and Sulzmann (58), a singlet electronic system of SiO by Smith and Liszt (59), AlO by Michels (60) and Johnson, Capella and Broida (61), and LaO by Murthy and Murthy (62).

\section{(c) Polyatomic molecules}

The rapid extension of astronomical researches into the infrared and radio regions has focussed increasing attention of polyatomic molecules, either known to exist in the atmospheres of late-type stars or in interstellar matter, or suspected of being of potential importance. The following is only a sample of the numerous investigations that have been carried out recently.

The high resolution infrared spectra of isotopic species of $\mathrm{CO}_{2}$ have been investigated by Oberly 
$(63,64)$; improved constants for this molecule have been calculated by Val (65), and its $2.7 \mu \mathrm{m}$ band has been treated by Kunitomo and Ninai (66). Measures of relative intensities in electronic bands of $\mathrm{CO}_{2}{ }^{+}$have been carried out by McCallum and Nicholls (67). The bending frequency of the $\mathrm{C}_{3}$ molecule has been measured by Liskow et al. (68), while the infrared spectrum of $\mathrm{O}_{3}$ has been the subject of a number of investigations by Lichtenstein et al. (69), Brewer and Wang (70) and Barbe, Secroun and Jouve (71). For $\mathrm{NO}_{2}$ there are compilations of molecular constants by Blank (72) and Ramaswamy and Shanmugan (73), and oscillator strenths by Gangi and Burnelle (74). The infrared spectrum of $\mathrm{N}_{2} \mathrm{O}$ has been investigated by Smith et al. (75), Tien, Modest and McCreight (76). Lowder (77), Margolis (78), Sokoloff and Javan (79). Bands of HCN at 14 microns have been described by Yin and Rao (80) while the microwave spectrum of $\mathrm{HCO}$ has been investigated by Bowater, Brown and Carrington (81). Isotopic bands of $\mathrm{H}_{2} \mathrm{O}$ in the infrared have been reported by Williamson, Rao and Jones (82) and Steenbeckeliers and Bellet (83) and the submillimetre spectrum of $\mathrm{H}_{2} \mathrm{O}$ by de Lucia et al. (84). The spectrum and structure of the $\mathrm{HO}_{2}$ free radical have been described by Jacox and Milligan (85).

\section{RESEARCH IN PROGRESS}

\section{(a) From the National Research Council of Canada}

\section{(reported by G. Herzberg and A. E. Douglas)}

The ultraviolet emission and absorption spectrum of HF has been studied by di Lonardo and Douglas and much more complete information has been obtained than available up to now. Similarly the absorption spectrum of $F_{2}$ in the vacuum ultraviolet has been studied by Douglas and Raymonda. The ground state constants of $F_{2}$ have been much improved.

In our program of studies of molecular ions $\mathrm{H}$. Lew has succeeded in observing an extensive spectrum of $\mathrm{H}_{2} \mathrm{O}^{+}$which in many ways is similar to the spectrum of $\mathrm{NH}_{2}$. Provisional values for the ground state constants have been obtained. They fit well with the constants for the Rydberg states of $\mathrm{H}_{2} \mathrm{O}$ which J. W. C. Johns is continuing to study. $\mathrm{H}_{2} \mathrm{O}^{+}$is an ion that almost certainly will be discovered sooner or later in the interstellar medium and possibly in comets.

The Lyman and Werner bands of $\mathbf{D}_{2}$ in the vacuum ultraviolet have been studied in absorption and emission, and much improved values for the molecular constants in the ground state and the excited states have been obtained by Bredhol and Herzberg. Also a study of the vibrational levels near the dissociation limit of HD has been initiated by Dabrowski and Herzberg.

\section{(b) From the National Bureau of Standards}

\section{(reported by Karl G. Kessler and Don Johnson)}

Spectroscopic work at NBS is going on in the optical region. Theoretical studies on molecular topics are also being carried out to compliment the experimental work.

In the optical region, considerable effort is still being spent on electronic spectra of diatomic molecules. An extended systematic analysis by J. D. Simmons of the CO absorption bands to the low lying valence states has recently been concluded. The seven excited valence states involved have been identified as belonging to two electronic configurations: $\pi^{3} \pi^{*}$ and $\sigma \pi^{*}$. A re-examination of the vacuum ultraviolet emission spectrum of $\mathrm{CO}$ has led to some interesting results. Two emission systems identified with $\mathrm{CO}$ for many years have now been assigned to $\mathrm{N}_{2}$. Two new band systems for $\mathrm{CO}$ have been located and the accidental predissociation in the $\mathrm{E}^{1} \pi$ state of $\mathrm{CO}$ has been confirmed.

P. H. Krupenie has completed an extensive critical review of the electronic spectrum of $\mathrm{O}_{2}$. A similar critical review of molecular nitrogen is in progress by Krupenie in collaboration with A. Loftus of the University of Oslo.

Several polyatomic molecules of particular interest for interstellar work have been studied in the microwave region. D. R. Johnson and F. J. Lovas have recently assigned the rotational spectrum 
of $\mathrm{CH}_{2} \mathrm{NH}$. Detailed centrifugal distortion analyses of the microwave spectra of $\mathrm{H}_{2} \mathrm{CS}$ and $\mathrm{NH}_{2} \mathrm{CHO}$ have been carried out by Kirchhoff and Johnson.

Critical reviews of laboratory microwave spectra of several interstellar molecules have been undertaken with an aim at reliably predicting all rotational transitions in those molecules which might be expected to be detectable with radio telescopes. Kirchhoff, Lovas and Johnson have completed such reviews for $\mathrm{H}_{2} \mathrm{CO}, \mathrm{H}_{2} \mathrm{CS}, \mathrm{NH}_{2} \mathrm{CHO}$, and $\mathrm{CH}_{2} \mathrm{NH}$. A collaborative effort with $\mathrm{R}$. Lees of the University of New Brunswick has produced a similar review of $\mathrm{CH}_{3} \mathrm{OH}$. $\mathrm{HCN}$ and $\mathrm{OCS}$ are presently under review by A. G. Maki. Krupenie and Lovas are nearing completion of similar reviews of $\mathrm{CO}$, $\mathrm{CS}$ and SiO.

Several molecules of astronomical interest are being studied under high resolution in the infrared. W. B. Olson has recently determined ground state rotational constants for $\mathrm{CH}_{3} \mathrm{D}$ and is presently analysing the $\gamma_{2}$ band of $\mathrm{CH}_{3} \mathrm{D}$ at $2200 \mathrm{~cm}^{-1}$. Ground state rotational constants have also been determined for $\mathrm{SiH}_{3} \mathrm{D}$ by $\mathrm{R}$. W. Lovejoy and W. B. Olson. $\mathrm{NO}_{2}$ is currently under investigation at high resolution by W. J. Lafferty and R. L. Sams. Maki and Sams are using a high temperature oven in order to observe $\mathrm{HCN}$ transition in highly excited rotational and vibrational levels. Work less directly applicable to astronomy is underway on $\mathrm{AsH}_{3}, \mathbf{P H}_{3}$ and $\mathrm{CS}_{2}$.

(c) From the University of California, Berkeley

(reported by J. G. Phillips and S. P. Davis)

Measures and analyses of the high dispersion rotational structures of TiO from $4000 \mathrm{~A}$ to $1.1 \mu \mathrm{m}$ are completed. Over 35000 identifications have been made in 7 band systems. The identifications are available on cards, IBM computer print-outs, and eventually on tapes and microfilm. These analyses have been used to derive improved TiO molecular constants. A similar program is being initiated on ZrO. Preliminary tests give assurance that we can readily resolve the more crowded rotational structure and apply the same programs of reduction and analysis that have proved so successful for TiO.

A program of measurement of lifetimes of selected levels in four systems of TiO has been initiated using an electric furnace and a fluorescence technique. Relative transition probabilities of bands of $\mathrm{ZrO}$ in the $4000-7000 \AA$ range are being measured on furnace photoelectric scans and photographs.

\section{(d) From the Astronomical Institute at Utrecht}

\section{(reported by Aert Schadee)}

Schadee has been working on the normalisation of Hönl-London factors and the definition of the molecular electronic transition moment. Furthermore prompted by high dispersion sunspot spectra, he is trying to find out from the literature, what kind of Zeeman splittings are to be expected for dominant molecules.

(e) From the Eidg. Technische Hochschule Zurich

$$
\text { (reported by K. Dressler) }
$$

We have begun work on a deperturbation study of the intensity distribution in the absorption spectrum of NO. The final aim of this work is the computation of synthetic absorption spectra of NO at different temperatures and resolutions. This is of interest, e.g. for studies of the upper atmosphere. Indeed, we are already in contact with Dr Wofsy at the Smithsonian Astrophysical Observatory in Cambridge, Mass., who needs such data in calculations of photo-dissociation rates and $U V$ reflection in the upper atmosphere.

\section{REFER EN CES}

1. Spectroscopic Data Relative to Diatomic Molecules, (1970,) Pergamon Press.

2. Bibliography on the High Temperature Chemistry and Physics, IUPAC Commission on High Temperature and Refractories, Ed. by M. G. Hocking (IUPAC) Imperial College. 
3. Anderson, R. 1971, At. Data (U.S.A.), 3, 227.

4. Rotational Structure in the Spectra of Diatomic Molecules, 1969, I. Kovacs, Adam Hilger Ltd. London.

5. Far-infrared Spectroscopy, 1970, K. D. Mooler and W. G. Rothschild, Wiley-Interscience.

6. Microwave Molecular Spectra, 1970, Walter Gordy and R. L. Cook. Wiley-Interscience.

7. Rydberg Series in Atoms and Molecules, 1971, A. B. F. Duncan, Academic Press, New York.

8. The Spectra and Structures of Simple Free Radicals: An Introduction to Molecular Spectroscopy, 1971, G. Herzberg, Cornell University Press, Ithaca.

9. Low Temperature Spectroscopy: Optical Properties of Molecules in Matrices, Mixed Crystals, and Frozen Solutions, 1971, B. Meyer, American Elsevier Pub. Co.

10. American Institute of Physics Handbook, 3rd edition, 1972, Section 7, Atomic and Molecular Physics (Ed. R. M. Crosswhite), Revised Tables of Diatomic Molecular Constants, by K. P. Huber.

11. Fay, Marenin, van Citters. 1971, J. Quant. Spect. Rad. Trans., 11, 1203.

12. Kepa, R., Rytel, M. 1971, Acta Phys. Polon., A39, 629.

13. Ogawa, M., Ogawa, S. 1972, J. Molec. Spectros., 41, 393.

14. Simmons, J. D., Tilford, S. G. $\quad$ 1971, J. Res. Nat. Bur. Stand., 75A, 455.

15. Kepa, R. et al. 1972, Acta Phys. Polon, A41, 377.

16. Green, S. et al. 1972, Phys. Rev., A5, 1614.

17. Meinel, H. 1972, Canad. J. Phys., 50, 158.

18. Miescher, E. 1971, Canad. J. Phys., 49, 2350.

19. Brown, Cole, Honey 1972, Molec. Phys., 23, 287.

20. Mizushima, M. 1972, Phys. Rev., A5, 143.

21. Welch, W. M., Mizushima 1972, Phys. Rev., A5, 2692.

22. Moore, E. A., Richards, W. G. 1971, Physica Scripta, 3, 223.

23. Elander, N., Lagerqvist, A. 1971, Physica Scripta, 3, 267.

24. Cornet, R., Dubois, I. 1972, Canad. J. Phys., 50, 630.

25. Green, D. W. 1971, Canad. J. Phys., 49, 2552.

26. Green, D. W. 1971, J. Phys. Chem., 75, 3103.

27. Phillips, J. G., Davis, S. P. 1971, Ap. J., 167, 209.

28. Lindgren, $\mathrm{B}$. private communication.

29. Linton, C. 1972, Canad. J. Phys., 50, 312.

30. Phillips, J. G. 1971, Ap. J., 169, 185.

31. Herzberg, G., Jungen, Ch. 1972 , J. Molec. Spectros., 41, 425.

32. Stephens, T. L., Dalgarno, A. 1972, J. Quant. Spectros., 41, 425; Trans. 12, 569.

33. The Hydrogen Wavelength Tables of G. H. Dieke, 1972, Ed. H. M. Crosswhite, Wiley, New York.

34. Schadee, A. $\quad 1971$, Astron. Astrophys, 14, 401.

35. Ajello, J. M. 1971, J. Chem. Phys., 55, 3158.

36. James, T. C. 1971, J. Chem. Phys., 55, 4118.

37. Pilling, Bass, Braun 1971, J. Quant. Spect. Rad. Trans., 11, 1593.

38. Roux, Effantin, d'Incan 1972, J. Quant. Spect. Rad. Trans., 12, 97.

39. Lowder, J. E. 1971, J. Quant. Spect. Rad. Trans., 11, 1647.

40. Jain, D. C. 1972, J. Phys. B( At. Mol. Phys.), 5, 199.

41. Maier II, B., Holland, R. F. $\quad 1972$, J. Phys. B(At. Mol. Phys.), 5, L118.

42. Judge, D. L., Lee, L. C. 1972, J. Chem. Phys., 57, 455.

43. Deuwer, Coxon, Setser 1972, J. Chem. Phys., 56, 4355.

44. Schoonveld, L. $\quad 1972$, J. Quant. Spect. Rad. Trans., 12, 1139.

45. Johnson, Marenin, Price 1972, J. Quant. Spect. Rad. Trans., 12, 189.

46. Querci, Querci, Kunde 1971, Astron. Astrophys., 15, 256.

47. Dalgarno, A., Wright, E. L. $\quad 1972$, Astrophys. J. Lett., 174, L49.

48. Copeland, G. E. 1972, J. Chem. Phys., 56, 689.

49. Michels, H. H. 1971, J. Quant. Spect. Rad. Trans., 11, 1735.

50. Hasson, V., Nicholls, R. W. 1971, J. Phys. B(At. Mol. Phys.), 4, 1769.

51. Farmer, Hasson, Nicholls 1972, J. Quant. Spect. Rad. Trans., 12, 635.

52. Bubert, H. 1972, J. Chem. Phys., 56, 1113.

53. Moskalenko, N. I., Mirumyants, S. O. 1971, Sov. Phys. J., 6, 7.

54. d'Incan, Effantin, Roux 1971, J. Quant. Spect. Rad. Trans., 11, 1215.

55. Murphy, R. E. $\quad 1971$, J. Chem. Phys., 54, 4852.

56. Hasson, V., Nicholls, R. W. 1971, J. Phys. B. (At. Mol. Phys.), 4, 1778 and 1789.

57. Jarmain, W. R. 1972, J. Quant. Spect. Rad. Trans., 12, 603. 
58. Fissan, H., Sulzmann, K. G. P. $\quad$ 1972, J. Quant. Spect. Rad. Trans., 12, 979.

59. Smith, W. H., Liszt, H. S. 1972, J. Quanj. Spect. Rad. Trans. 12, 505.

60. Michels, H. H. 1972, J. Chem. Phys., 54, 665.

61. Johnson, Capelle, Broida 1972, J. Chem. Phys., 65, 663.

62. Murthy, N. S., Murthy, B. N. 1972, J. Phys. B. (At. Mol. Phys.) 5, 714.

63. Oberly, R. E. $\quad 1970$, Ohio State University thesis, University Microfilms No. 70-26343.

64. Oberly, R. E. et al. 1971, J. Molec. Spectros., 40, 356.

65. Val, J. L. 1971, J. Molec. Spectros., 40, 367.

66. Kunitomo, T., Ninai, S. 1972, Japan. J. Appl. Phys., 11, 503.

67. McCallum, J. C., Nicholls, R. W. 1972, J. Phys. B. (At. Mol. Phys.), 5, 1417.

68. Liskow, Bender, Schaefer 1972, J. Chem. Phys., 56, 5075.

69. Lichtenstein, Gallagher, Clough 1971, J. Molec. Spectros., 40, 10.

70. Brewer, L., Wang, J. L. 1972, J. Chem. Phys. 56, 759.

71. Barbe, Secroun, Jouve 1972, Comptes Rendus, 274B, 759.

72. Blank, R. E. 1970, Michigan State University thesis, Univ. Microfilms No. 71-2035.

73. Ramaswamy, K., Shanmugam, G. 1972, Acta. Phys. Polon., A41, 3.

74. Gangi, R. A., Burnelle, L. 1971, J. Chem. Phys., 55, 843 and 851 .

75. Smith, D. F. et al. 1972, Spectrochim. Acta, 28A, 86.

76. Tien, Modest, McCreight 1972, J. Quant. Spect. Rad. Trans., 12, 267.

77. Lowder, J. E. $\quad$ 1972, J. Quant. Spect. Rad. Trans., 12, 873.

78. Margolis, J. S. 1972, J. Quant. Spect. Rad. Trans., 12, 751.

79. Sokoloff, D. R., Javan, A. 1972, J. Chem. Phys. 56, 4028.

80. Yin, P. K. L., Rao, N. 1972, J. Molec. Spectros., 42, 385.

81. Bowater, Brown, Carrington 1971, J. Chem. Phys., 54, 4957.

82. Williamson, Rao, Jones 1971, J. Molec. Spectros., 40, 372.

83. Steeveckeliers, G., Bellet, J. 1971, Comptes Rendus, 273B, 471.

84. de Lucia, F. C., et al. 1972, Phys. Rev., A5, 487.

85. Jacox, M. E., Milligan, D. E. 1972, J. Molec. Spectros., 42, 495. 